\title{
LA JUDICIALIZACIÓN DE LA PROTESTA SOCIAL: ENTRE ESTRATEGIA REPRESIVA Y BÚSQUEDA DE UN ÁMBITO DE PROTECCIÓN
}

\author{
Centro de Investigación y Defensa Sur ${ }^{121}$
}

\section{Introducción: la protesta social y su judicialización}

El siglo XXI ha estado marcado por protestas y movimientos sociales que elevan la dignidad como símbolo que aglutina diferentes demandas y, que a diferencia del siglo XX, no tienen una base político-ideológica común ni están liderados por partidos políticos. En Chile se destacan las protestas estudiantiles de los años 2006 y 2011, la protesta mapuche, el movimiento feminista, entre otros. Pero sin duda, el ciclo de protestas sociales en el país alcanzó su punto de mayor masividad y adhesión ciudadana en octubre de 2019, con la aglutinación de los distintos movimientos sociales que se habían desarrollado en las últimas décadas. Consignas tales como "No son 30 pesos, son 30 años", dan cuenta de una fuerte crítica a la herencia dictatorial y la incapacidad de los distintos gobiernos de otorgar las condiciones mínimas para vivir dignamente.

121 El Centro de Investigación y Defensa SUR (CIDSUR), con sede en Temuco, es una organización compuesta por un equipo multidisciplinario de profesionales mapuche y no mapuche. Durante la última década se ha realizado defensa jurídica especializada, y se han documentado múltiples violaciones de derechos humanos de niños, niñas, adolescentes y adultos/as, que producto de su participación en actos relacionados a la protesta social, han sido perseguidos/as penalmente o han visto vulnerados sus derechos fundamentales (individuales y colectivos) por parte de agentes del Estado. CIDSUR nace antela realidad social de las últimas décadas en el sur de Chile, donde cientos de líderes mapuche y sus autoridades políticas y espirituales han sido encarcelados usando tanto la legislación penal común como leyes especiales v.gr. Ley que Califica Conductas Terroristas, La Ley de Seguridad del Estado, y la Ley de Control de armas, con un exponencial incremento de la represión y respuesta militarizada a las demandas de derechos indígena individuales y colectivas. En estas circunstancias CIDSUR ha litigado en casos asociados a los efectos de la violencia de Estado, la criminalización y las detenciones ilegales. De igual modo se ha patrocinado causas en contra de agentes del Estado por graves vulneración del derecho a la vida, la integridad física y psíquica de personas indígenas y no indígenas que han sido víctimas de tortura, tratos crueles, inhumanos y degradantes, arrestados, heridos y asesinados por las fuerzas policiales. En denuncia de estos hechos hemos enviado reportes a diferentes organismos de Naciones Unidas, y una vez agotada la vía interna, elevado casos ante la Comisión Interamericana de Derechos Humanos. centroidsur@gmail.com 


\section{Capitulo 5. Página 95}

En este contexto, la justicia aparece desempeñando un rol ambivalente. Por un lado, los órganos judiciales tienen el deber constitucional de velar por el respeto y garantía de los derechos fundamentales de los ciudadanos mientras que, por otro, la justicia aparece como la herramienta más inmediata a la que recurren los gobernantes para hacer frente a toda protesta que demande una transformación estructural de la sociedad. Esto explica la aparición en la esfera pública leyes que implican la creación de nuevos delitos y/o aumento de penas ${ }^{122}$ que amplían las facultades de militares ${ }^{123}$, así como también prácticas como los encarcelamientos preventivos masivos.

A este fenómeno lo denominamos como judicialización de la protesta social, la que puede entenderse como el encauzamiento por la vía judicial de conflictos cuya naturaleza es eminentemente política ${ }^{124}$. A la instrumentalización de la justicia efectuada con el objeto de reprimir la protesta social, la llamaremos "judicialización represiva"; mientras que si el recurso a la justicia tiene como fin obtener resguardo y protección frente a los delitos y violaciones de derechos fundamentales cometidas en la represión de la protesta social, la denominaremos "judicialización defensiva o protectora".

A lo largo de este texto intentaremos mostrar cómo la actual judicialización de la protesta social chilena parece ser más eficaz en su faz represiva y altamente ineficaz como instrumento de protección. Creemos que en el actual contexto de conflicto social y crisis sanitaria, la reflexión que proponemos resulta pertinente en la discusión por una nueva constitución, en particular, en lo que respecta a la necesidad de un reconocimiento efectivo del derecho a protesta, el cual no se encuentra garantizado en la Constitución de $1980^{125}$. Esto porque el actual condicionamiento a autorizaciones administrativas al que se somete el ejercicio del derecho a manifestarse ocasiona que incluso en protestas pacíficas, las Fuerzas de Orden y Seguridad puedan disolverlas, lo que en la mayor parte de los casos se produce de manera violenta ${ }^{126}$.

En un breve ejercicio de retrospectiva, echando mano de la experiencia de la década de trabajo en WALLMAPU, en el final de este texto procuraremos mostrar cómo lo ocurrido en Chile a partir de octubre de 2019 aparece como una especie déjà vu del accionar del sistema judicial respecto del tercer ciclo de movilización social mapuche (Pairican, 2014), develando al sistema judicial como una instancia inapropiada para procesar conflictos sociales graves, susceptible de una fuerte instrumentalización política y padecer graves falencias en el resguardo de DD.HH. y el control del derecho punitivo.

122 v. gr. Ley $\mathrm{N}^{\circ} 21.208$ que modifica el Código Penal para tipificar acciones que atenten contra la libertad de circulación de las personas en la vía pública a través de medios violentos e intimidatorios, y fija las penas aplicables al saqueo en las circunstancias que indica.

123 Como la Reforma constitucional para que la FFAA resguarden infraestructura calificada como crítica: Boletín 1308607, Proyecto de reforma constitucional que regula estado de alerta para prevenir daños a infraestructura crítica.

124 Conforme define la Real Academia Española, judicializar es "Llevar por vía judicial un asunto que podría conducirse por otra vía, generalmente política."

125 Actualmente, la regulación del derecho a protesta, entendido como el ejercicio del derecho a reunión y la libertad de expresión, se encuentra entregado a normas reglamentarias (Art 19 № 13 CPR). En particular es el Decreto Supremo 1086 el que establece las condiciones para poder reunirse masivamente en lugares públicos, entregando la prerrogativa de autorizarlas a las Gobernaciones.

126 Ver el capítulo escrito por los mismos autores en el Anuario 2018 que se refiere al comando Jungla y el asesinato de Camilo Catrillanca. (CIDSUR, 2019) 


\section{Capitulo 5. Página 96}

En cuanto a la metodología utilizada este trabajo, en relación al contexto nacional, priman métodos cuantitativos aplicados sobre fuentes informadas por el Ministerio Público, el Poder Judicial y el Instituto Nacional de Derechos Humanos, junto al análisis del discurso respecto de informaciones de prensa. En relación al contexto regional de La Araucanía, aplicamos también técnicas cuantitativas, sin embargo tienen preeminencia la observación participante y la etnografía en tribunales y comisarías, la revisión de sentencias y audios permitiendo el análisis de casos.

\section{La judicialización represiva}

Un día después de iniciado el Estallido Social o revuelta popular, el sábado 19 de octubre, se publicaba en Diario Oficial el Decreto Supremo № 472, por medio del cual el Gobierno decretaba el Estado Constitucional de Emergencia en las provincias de Santiago, Chacabuco, y dos comunas de la Región Metropolitana ${ }^{127}$. Cabe destacar que el Decreto fue elaborado el 18 de octubre, lo cual devela un inmediato manejo represivo de las protestas ciudadanas $\mathrm{y}$, por ende, una renuncia a entregar soluciones políticas. Asimismo, su elaboración se produce en el contexto de un fuerte cuestionamiento a las actuaciones del Presidente de la República, en particular, por haber sido visto en un restaurant de pizzas en Santiago en medio de una jornada de grandes manifestaciones, lo que ha sido definido como una de las señales más claras de la desconexión del gobierno con las demandas ciudadanas.

En tanto, para las comunas de Temuco y Padre Las Casas de la IX Región, el Estado de Emergencia fue dictado el 20 de octubre mediante el Decreto Supremo № 483, publicado el mismo día en el Diario Oficial ${ }^{128}$.

La declaración del Estado de Excepción no sólo permitió la presencia de militares en las calles y, en la práctica cercenar la libertad de movimiento y los derechos de reunión y protesta, sino que además, en el escenario estrictamente judicial, otorgó al Ministerio Público y al querellante generalmente el Gobierno y empresas afectadas - mayores posibilidades de obtener medidas cautelares privativas de la libertad de los manifestantes detenidos mediante la invocación de la circunstancia que agrava la responsabilidad criminal, por cometer el delito con ocasión de tumulto o conmoción popular ${ }^{129}$. A continuación, expondremos algunas de las situaciones que logramos identificar y que dan cuenta de la judicialización represiva.

\section{Detenciones masivas}

El primer momento de una respuesta represiva a la protesta social lo constituye el actuar policial

127 Respecto a este último punto: https://www.elmostrador.cl/noticias/pais/2019/10/19/la-pizza-mas-cara-de-pinera-la-cadena-deerrores-del-presidente-que-prendieron-fuego-al-estallido-social/

128 Decreto 843 del Ministerio del Interior de 20 de octubre de 2019.

129 El artículo $12 \mathrm{~N}^{\circ} 10$ del Código Penal establece que se considera circunstancia agravante "cometer el delito con ocasión de incendio, naufragio, sedición, tumulto o conmoción popular u otra calamidad o desgracia". 


\section{Capitulo 5. Página 97}

en las marchas. Según Carabineros, al 4 de diciembre de 2019, se informaban 18.500 detenciones en contexto del Estallido Social ${ }^{130}$. A pesar del gran número de detenciones efectuadas en estas circunstancias, el Ministerio Público decidió no iniciar investigación en 30.313 causas ${ }^{131}$ asociadas al Estallido Social, lo que corresponde al 21,16\%, mientras que no perseveró en la investigación en otras 1.378 y aplicó el principio de oportunidad en 4.566 causas (DESC, 2020).

Según la Fiscalía, una importante cantidad de los detenidos quedó apercibido de conformidad al Art. 26 del Código Procesal Penal, motivo por el cual la legalidad de las detenciones fue controlada tan solo en el $16,87 \%$ de los casos, quedando más del $85 \%$ de actuaciones policiales sin control por parte de algún Tribunal ${ }^{132}$. Los Tribunales de Garantía en tanto, declararon ilegal la detención de 1.928 imputados, 77,7\% más respecto del periodo del año anterior ${ }^{133}$. Las cifras revelan la existencia de numerosas detenciones masivas, sin trabajo táctico o de inteligencia, donde más que perseguir al infractor, se detiene al que se alcanza.

La labor de los Tribunales pareciera ser bastante garantista, en general las cifras dan cuenta de un control más severo de la legalidad de las detenciones y un menor acceso a la solicitud de prisiones preventivas si se comparan con un periodo de normalidad social ${ }^{134}$. Sin embargo, los números aisladamente considerados no alcanzan a dar cuenta del alto nivel represivo sufrido por los ciudadanos ni de la pobre función cautelar de la judicatura ${ }^{135}$.

$130 \mathrm{Hkb}$ En detalle, las detenciones informadas a la prensa por Carabineros correspondían a 9.426 por desórdenes y 4.969 por saqueos o robo en lugar no habitado. Disponible en https://www.meganoticias.cl/nacional/284062-balance-carabineros- detenidos-saqueosestallido-social.html (visitado por última vez el 12 de mayo de 2020). Según un Informe del Departamento de Desarrollo Institucional de la Corporación Administrativa del Poder Judicial y las Direcciones de Estudios y Comunicaciones del Poder Judicial, entre el 18 de octubre de 2019 y el 13 de enero de 2020, a los Juzgados de Garantía ingresaron 143.215 causas, un 6,5\% menos que igual periodo del año anterior que marcó 153.108 causas. Al examinar el número de imputados aparece que este creció un 1,5\%, de 176.803 a 179.442. Las detenciones en flagrancia por su parte se incrementaron de 50.478 audiencias en el periodo de 2018, a 55.586 en 2019 , un 10,1 \% más. Y el número de formalizados en el periodo se incrementó en un 1,3 \%, 47.569 personas el año 2019 frente a las 44.694 del 2018.

131 La aparente diferencia entre números de detenciones y de causas relacionadas con el Estallido Social se debe al uso de fuentes de información distintas (Carabineros, Fiscalía y Poder Judicial) que no consideran los mismos periodos.

132 Informe Estadístico Anual 2019 de la Fiscalía Nacional. A mayor abundamiento, entre el 18 de octubre y el 31 de diciembre de 2019 , pasaron a audiencia de control de detención (ACD) 54.442 imputados, un 0,4\% más que en el mismo periodo del año anterior. De estos, 36.745 fueron formalizados, lo que representa un 16,6\% más, comparativamente. Los imputados que fueron apercibidos ascienden a 269.303, un 2,5\% más. Del total de ACD, el 84\% correspondían a personas detenidas en flagrancia, que es otro dato que permite relacionar a los detenidos con la situación del Estallido Social.

133 Informe del Departamento de Desarrollo Institucional de la Corporación Administrativa del Poder Judicial y las Direcciones de Estudios y Comunicaciones del Poder Judicial, 2019.

134 Según el mismo informe del Poder Judicial, las prisiones preventivas solicitadas por el Ministerio Público alcanzaron a 6.470 imputados, la que fue concedida en primera instancia respecto de 5.793 personas. Esto significa que la solicitud de prisión preventiva fue acogida en el 89,5\% de los casos, lo que indicaría, según esta fuente, una leve disminución respecto del año anterior, en que este porcentaje alcanzaba el 91,2\%. El número de apelaciones respecto de la resolución que concede la prisión preventiva se elevó a 1.195 casos (20,6\%), de los cuales, las Cortes de Apelaciones revocaron la medida solo para 89 imputados (un 7,4\% de las apelaciones), lo que da un total de 5.778 personas afectas a la medida cautelar más gravosa de nuestro ordenamiento jurídico, que en comparación con igual periodo del año anterior, implica 871 personas menos.

135 El único indicador que permite concluir la asociación de los delitos informados con la protesta social, según informaba a la prensa la propia Ministra Suprema Gloria Ana Chevesich, es el que da cuenta de delitos cometido por agentes estatales en contra de particulares. En efecto, el periódico La Tercera publicaba el día 19 de febrero: “del análisis de los datos se advierte una variación del comportamiento de determinados delitos por su posible vínculo con la situación social”. Esto en específico, dijo Chevesich, "se percibe con mayor nivel de precisión en la vinculación de determinados delitos a violaciones a los DD.HH., estos son, aquellos cometidos por agentes del Estado en contra de particulares". Disponible en https://www.latercera.com/nacional/noticia/57-las-causas-concluidas-tras18-no-se-inicio-investigacion/1015461/ 
En efecto, es al examinar el tipo de delitos que se han llevado a audiencia de control de detención (ACD), cuando aparece de manifiesto la judicialización represiva. Del listado de 20 delitos ofrecido por el MP en su Informe Estadístico Anual 2019, todos experimentan una baja porcentual considerable, resultando una situación paradójica, pues los delitos que más preocupan a la opinión pública en realidad descendieron entre un 10 y casi un $50 \%{ }^{136}$.

Ahora bien, los delitos que incrementaron su presencia en las ACD son solo aquellos asociados al Estallido Social: el robo en lugar no habitado y la receptación, que suelen relacionarse con los saqueos, subieron un 113,6\% y un 17\%, respectivamente; los desórdenes públicos propios de marchas y movilizaciones, se incrementaron en 4.433,9\%; mientras que los daños simples un $13,1 \%$ y el maltrato de obra a Carabineros un $47,2 \%$.

La naturaleza de los delitos sometidos a ACD, desde el punto de vista criminológico no constituyen delitos graves, toda vez que no se afectan bienes jurídicos de mayor trascendencia, correspondiendo generalmente a la propiedad y al orden público. En abstracto, atendiendo a la norma ${ }^{137}$ y en la imposibilidad de considerar aquí la situación particular de cada imputado, ninguno de estos delitos ameritaría prisión preventiva, dada la gravedad de los mismos, la pena asignada, la inexistencia de víctima humana y el bajo o nulo peligro para la seguridad de la sociedad. Sin embargo, las cifras del MP indican que en este periodo se decretaron 3.859 prisiones preventivas y 173 internaciones provisorias, lo que representaría una baja global de $-2,5 \%$ de ambas medidas cautelares.

La aparente baja no tiene ninguna relevancia desde una óptica garantista, pues la naturaleza de los delitos controlados haría improcedente esas medidas cautelares en una situación normal. La represión es patente y hasta el MP indica en el citado informe que "Se observa un comportamiento similar de las prisiones preventivas y las internaciones provisorias respecto de un periodo normal, existiendo un criterio más severo de las instituciones del sistema de justicia si se considera la penalidad de los delitos llevados a Audiencia de Control de Detención ${ }^{138}$."

\section{Criminalización y endurecimiento de penas respecto de hechos asociados a protesta social}

La respuesta punitiva del Estado frente al Estallido Social estuvo marcada también por un aumento explosivo en la utilización de la Ley 12.972 sobre seguridad del Estado (LSE). Tal como señala Villegas $(2013)^{139}$, dicha legislación se enmarca dentro del denominado Derecho Penal de lucha donde el Estado ya no dialoga con sus ciudadanos para mantener la vigencia de la norma, sino que combate males y peligros y, por ello, la pena deja de ser en estricto rigor la sanción a un hecho cometido y, más bien se dirige al aseguramiento frente a hechos futuros.

\footnotetext{
136 Lesiones menos graves $-18.5 \%$, hurto simple $-40.4 \%$, amenazas simples $-15,6 \%$, lesiones leves $-19,0 \%$, conducción en estado de ebriedad $-14,7 \%$, hurto falta $-49,7 \%$, hurtos simples de 4 a 40 UTM $-39,2 \%$, desacato $-13,5 \%$, microtráfico $-39,6 \%$. porte de arma $-44,1 \%$, robo con intimidación $-33,5 \%$, robo en lugar habitado $-16,6 \%$, robo por sorpresa $-40,7 \%$, robo en bienes nacionales de uso público $-31,2 \%$, amenazas condicionadas contra personas y propiedad $-10,2 \%$.

137 Art. 140 Código Procesal Penal.

138 El resaltado es nuestro.

139 Villegas, Myrna. Estado de Excepción y antiterrorismo en Chile. Criminalización de la protesta social con especial referencia a los indígenas. Revista de Derecho Penal y Criminología. Año 3. N 6. Julio 2013. pp. 325.
} 
Este aseguramiento se da a través de tres características fundamentales: adelantamiento de la punición a través del castigo de actos preparatorios, aumento de penas y restricción o supresión de garantías procesales. Así, el artículo 23 de la Ley de Seguridad del Estado adelanta el momento de sancionar un hecho no solo cuando este es ejecutado, sino que además "la proposición y la conspiración para cometer alguno de los delitos sancionados en esta ley, serán castigadas con la pena señalada al delito consumado, rebajada en uno o dos grados".

Asimismo, declara un aumento de las penas para cada uno de los hechos que bajo la ley común tendrían penas sustancialmente menores, como ocurre por ejemplo con el delito de desórdenes públicos, aumentando su sanción desde los 61 a 541 días hasta los 5 años de cárcel (Art. 7 en relación al Art. 5 LSE). Finalmente, se establecen normas especiales para aquellos que entreguen antecedentes acerca de la comisión o preparación de tales actos, dejándolos inclusive sin sanción (Art. 23 a) LSE), en evidente desmedro de la presunción de inocencia de los imputados acusados por el delator compensado.

Es importante destacar que esta normativa solo puede ser aplicada por querella o denuncia interpuesta por el Gobierno. Según las cifras entregadas por el Ministerio del Interior al 22 de febrero de 2020 durante los primeros los meses del estallido de la crisis social en el país, el Gobierno presentó un total de 504 querellas invocando la LSE, cifra considerablemente mayor a las 8 querellas presentadas el año anterior en base a esta ley ${ }^{140}$.

Los efectos concretos de la invocación de esta norma de excepción aparecen encarnados en la figura del profesor Roberto Campos Weiss, quien estuvo sometido a prisión preventiva durante dos meses, acusado de daños a un torniquete de la estación del Metro San Joaquín en Santiago. La pena asignada al delito de daños, según disposiciones del Código Penal, fluctúa entre los 61 y 540 días, por lo que se cumpliría en un régimen de libertad. Sin embargo, con la invocación de la ley de excepción, el delito pasa a atentar contra la seguridad del Estado y su pena podría alcanzar los 5 años ${ }^{141}$, lo que permitió mantenerlo privado de libertad el tiempo indicado.

En forma paralela a la invocación de la LSE, en este ambiente de excepción constitucional fue aprobada y publicada en el Diario Oficial el día 30 de enero de 2020, la Ley № 21.208, que "Modifica el Código Penal para tipificar acciones que atenten contra la libertad de circulación de las personas en la vía pública a través de medios violentos e intimidatorios, y fija las penas aplicables al saqueo en las circunstancias que indica". Los nombres públicos de esta ley son claramente indiciarios de la realidad nacional. El Gobierno la defendía como la "Ley Antisaqueos" y para gran parte de la opinión pública era la ley del "que baila pasa", en referencia a una nueva forma de manifestarse que exigía de los conductores parte de un baile para permitirles el paso. Es así como, frente a nuevas formas de protesta - percibidas como pacíficas por los manifestantesel ejecutivo reacciona creando nuevos tipos penales, sancionando como delitos conductas que previamente no lo eran, o bien aumentando las penas de los delitos ya existentes.

140 https://www.soychile.cl/Santiago/Sociedad/2020/02/22/640021/Mas-de-500-querellas-por-Ley-de-Seguridad-del-

Estado-sepresentaron-tras-la-crisis-social.aspx

141 Causa Rol Nº 2923 - 2019 del 11 Juzgado de Garantía de Santiago. 


\section{La judicialización represiva de la protesta chilena en La Araucanía}

Una de las imágenes más emblemáticas de las protestas en La Araucanía, es la que muestra el derribamiento de la estatua de Pedro de Valdivia y el decapitamiento del busto del militar Dagoberto Godoy, cuya cabeza fue posteriormente colgada en la mano del toqui Caupolicán en una de las principales esquinas de la ciudad. A fin de perseguir actos como estos, el fiscal regional de La Araucanía, Cristian Paredes ${ }^{142}$, según indica en su cuenta pública del año 2019, entre otras medidas decidió crear un foco investigativo especial a cargo de la BICRIM de la PDI, con el objeto de investigar los daños a la propiedad pública: semáforos y monumentos nacionales. Hechos como estos, según indicaba él mismo, se suscitaban en los momentos en que las protestas alcanzaron sus "niveles más altos". En la misma línea, definió un equipo de investigación especial para robos (no obstante, su escasa incidencia regional) y desórdenes, el cual estaba formado por cuatro fiscales, cuatro abogadosasistentes y un analista, con el fin de investigar y coordinar acciones con policías y el municipio.

Las cifras en la región, según la cuenta anual de la Fiscalía Regional de La Araucanía, indican que desde el inicio del Estallido al 31 de diciembre de 2019, en la Región de La Araucanía 729 personas fueron llevadas a ACD, todas supuestamente detenidas en flagrancia. El $72 \%$ de los delitos corresponden a desórdenes públicos, el $6 \%$ a atentados de vehículos motorizados en movimiento, $5 \%$ daños simples y solo un $2 \%$ a robo en lugar no habitados, con el que se relacionan los saqueos. En el periodo indicado hubo 339 formalizados y 427 pasaron a procedimiento simplificado dado que se trataba de simples delitos y faltas con penas menores a 540 días de cárcel.

Como es común ya en el HABITUS de fiscales, tanto a nivel nacional como regional, las prisiones preventivas son exhibidas como verdaderos $\operatorname{logros}^{143}$ de gestión. En su cuenta pública, Paredes resaltaba que la fiscalía consiguió que 32 imputados quedaran en prisión preventiva y 4 adolescentes en internación provisoria. El fiscal regional indicó que se utilizarían todas las herramientas legales para "perseguir con la mayor severidad" los delitos asociados al Estallido, dedicando equipos "preferentemente" a estas tareas, no obstante la labor sea "extensa y ardua", pues no tolerará "el vil amparo que algunos han buscado en las demandas sociales para su aprovechamiento personal en la comisión de delitos."

142 Cristián Paredes asume el cargo de Fiscal Regional de La Araucanía en agosto del año 2013. En los años anteriores a su nombramiento, estuvo a cargo de varias investigaciones contra autoridades y activistas mapuche, destacándose como el fiscal a cargo de la investigación por Ley Antiterrorista contra los Lonko Pascual Pichun y Aníceto Norín, caso que finalmente acarreó la condena al Estado Chileno por parte de la Corte Interamericana de Derechos Humanos en el año 2014. Asimismo, en sus funciones como fiscal adjunto, ordenó las intervenciones telefónicas a un abogado defensor de imputados mapuche, lo que significó una condena contra el Fisco de Chile (Corte Suprema Rol N²765-2009).

143 Véase por ejemplo el anuncio del primer imputado sometido a prisión preventiva por incumplir la cuarentena en la crisis sanitaria. 


\section{La primera condena por saqueo de Chile ${ }^{144}$}

Se ha podido presenciar en el Juzgado de Garantía de Temuco la audiencia de control de detención de tres mujeres sin antecedentes penales, una madre y sus dos hijas, una de ellas menor de edad. Detenidas durante las primeras manifestaciones de octubre, se les imputó el delito de "robo en lugar no habitado" por haber destruido una vitrina de una tienda comercial céntrica de la cual se sustrajo una caja con piezas de baterías de ollas, una batidora y una máquina chocolatera. Sosteniéndose principalmente sobre testimonios policiales, la fiscalía solicitó la prisión preventiva, aduciendo a la situación de flagrancia en la cual fueron detenidas y al contexto actual de Estado de Emergencia como un agravante. Para la fiscalía las mujeres representaban claramente "un peligro para la seguridad de la sociedad" visto "la gravedad del delito y la circunstancia, forma y modalidad de actuar en pandilla" y al aprovecharse del estado de conmoción para incurrir a un delito ajeno al contexto social. En respuesta, el defensor público subraya la ausencia de pruebas de la participación de las imputadas en la destrucción de la vitrina y, además la desproporcionalidad de la solicitud de prisión preventiva para personas sin antecedentes judiciales. Sin embargo la Magistrada decretó la prisión preventiva para las dos adultas, y el arresto domiciliario nocturno para la menor al considerar "la libertad de las imputadas representa un peligro para la sociedad" y la existencia de un agravante por haber cometido el delito en circunstancias de "una situación de contingencia del país en el cual existe claramente una sensación de inseguridad por parte de todos los ciudadanos lo que indica que esto reviste un carácter de gravedad que debe ser ponderado por el juez al momento de decretar la prisión preventiva".

En este caso es posible observar cómo el tribunal hace un uso indiscriminado de la prisión preventiva para una madre y su hija, y mientras esta su otra hija menor presente, invocando el artículo 12 número 10 del Código Penal que contempla un agravante en caso de cometer un delito en contexto de "tumulto o conmoción popular". Si bien el Estado de Emergencia no constituye legalmente un agravante, la jueza la iguala con las condiciones antes mencionadas para poder justificar una medida cautelar de última ratio considerada como la más gravosa del ordenamiento jurídico. La invocación de disposiciones especiales para tipificar delitos de penas bajas en un contexto de movilización social que justamente pone en tela de juicio las injusticias y desigualdades socioeconómicas da cuenta del carácter político de las decisiones judiciales. Finalmente, las dos mujeres quedaron un mes en prisión preventiva antes de ser sometidas a un procedimiento abreviado donde las imputadas tuvieron que reconocer su responsabilidad y ser condenadas. A través de este caso que se transformara en la primera condena por saqueo en Chile, vemos cómo el uso y abuso de la prisión preventiva se convierte no solo en herramienta represiva y disuasiva antes las movilizaciones sociales, pero también un medio de presión para acudir a procedimientos abreviados y condenas. El peso probatorio dado por el tribunal —aún

144 RIT 10347 - 2019 del Juzgado de Garantía de Temuco. 
presuntivamente- al testimonio de los funcionarios policiales aprehensores y que permitió la prisión preventiva en contra de la madre, ha sido una constante en las causas seguidas en contra de la protesta social mapuche.

\section{Ciudadano Mapuche sueco acusado de porte de elemento explosivo ${ }^{145}$}

En noviembre del 2019 fue detenido Christoffer Quidel Larsson, ciudadano mapuche- sueco, en el contexto de manifestaciones sociales en el centro de la ciudad de Temuco. Según lo manifestado por el Ministerio Público en la audiencia de formalización, la detención se habría producido debido a que el imputado mantenía en su poder botellas que "tenían olor a parafina" las que corresponderían a "Las llamadas bombas molotov"146. En base a estos hechos, el órgano persecutor formalizó al imputado por el delito de porte de elemento explosivo, contemplado en el Art. 14 de la Ley 17.798 sobre control de armas, decretándose la medida cautelar de prisión preventiva.

El primer contacto entre CIDSUR y Christoffer Quidel Larsson se produce en el Centro de Cumplimiento Penitenciario de Temuco, donde permanecía en prisión preventiva. Tras constituirse el patrocinio y revisarse los antecedentes de la carpeta de investigación, se pudo evidenciar una serie de circunstancias que daban cuenta de la irregularidad del proceso y de la falta de objetividad con que el Ministerio Público había llevado a cabo la persecución penal.

En primer lugar, se tuvo acceso a un informe pericial químico que daba cuenta del contenido de las botellas que fueron incautadas al imputado. Dicho informe indicaba que diez botellas contenían agua y pintura, sin propiedades inflamables, mientras que solo una botella de plástico de 500cc habría resultado positivo a líquido desconocido con propiedades inflamables. Lo relevante de este informe pericial es que había sido evacuado con anterioridad al control de detención, siendo un antecedente que era conocido tanto por la fiscalía como por la defensoría penal pública, quien asumió la defensa del imputado en dicha audiencia. A pesar de contar con este antecedente, la fiscalía igualmente formalizó por el supuesto porte de "bombas molotov", aun cuando a la luz de la información científica proporcionada por el peritaje, dicha tesis quedaba sin sustento, situación que tampoco fue aclarada por la defensa ante el juez que decretó la prisión preventiva.

Una vez asumido el patrocinio por CIDSUR, se solicitó el sobreseimiento de la causa, argumentando que los hechos por los cuales se había formalizado a Christoffer Quidel no eran constitutivos de delito, ya que los elementos incendiarios indicados por la fiscalía no existían. Tal como se indicó previamente, el informe pericial químico había indicado que las botellas de vidrio que portaba el imputado contenían agua y pintura no inflamable, las cuales incluso fueron expuestas a fuego directo sin que explosionaran.

145 Rit: 11003-2019 Juzgado de Garantía de Temuco.

146 Audiencia de control de detención y de formalización, 8 de noviembre de 2019, RIT 11003 - 2019, Juzgado de Garantía de Temuco. 
A pesar de la existencia de estos antecedentes desde antes de la formalización, es en esta audiencia donde por primera vez se exponen ante la judicatura, quien tiene la posibilidad de evaluarlos en los siguientes términos: "El Tribunal estima que, no obstante lo señalado en el sentido que hubo antecedentes después de 2 horas en cuanto a las pericias de las botellas encontradas en poder del imputado y, se encontró que una de ellas al menos tenía un líquido inflamable, circunstancia que pudo y debió hacerse presente en la audiencia de formalización, como para contar con mayor cúmulo de antecedentes, es una omisión que el tribunal por ahora no califica pero que de alguna forma conllevó a la aplicación de la medida cautelar que se cuestiona."

A pesar de que en dicha oportunidad no se dio lugar al sobresemiento definitivo por la posibilidad de que los hechos fueran constitutivos de "otro" delito, el tribunal estableció claramente que no se estaba frente al delito de porte de artefactos incendiarios.

En razón de ello, se solicitó la sustitución de la prisión preventiva, ante lo cual la fiscalía manifestó su oposición a pesar de la existencia de un pronunciamiento jurisdiccional respecto a la no concurrencia del delito por el cual había formalizado. Finalmente, el Juzgado de Garantía de Temuco accedió a la solicitud de la defensa particular, modificando la medida cautelar a un arresto domiciliario, resolución que fue confirmada por la Corte de Apelaciones de Temuco tras la apelación verbal presentada por el ente persecutor. Semanas más tarde, específicamente el 30 de enero de 2020, el Ministerio Público decidió sustituir la formalización y requerir en procedimiento simplificado por el delito de "Porte de elementos conocidamente destinados a cometer el delito de incendio" del Art 481 del Código Penal, delito que tiene asignada una pena de presidio menor, por lo que, en caso de condena, podría cumplir mediante una pena sustitutiva no privativa de libertad o, que incluso, podría darse por cumplida en base a los 22 días que permaneció en prisión preventiva.

\section{La judicialización defensiva (o protectora)}

Diversos organismos internacionales encargados de la promoción y protección de derechos humanos, han constatado las graves y generalizadas vulneraciones ocurridas en Chile a partir de octubre de 2019 mediante el envío de misiones para constatar en el territorio las denuncias de los ciudadanos. Así, encontramos los informes de Amnistía Internacional, el emanado desde Human Rights Watch (HRW), el de la Comisión Interamericana de Derechos Humanos (CIDH) y el informe del Alto Comisionado de las Naciones Unidas para los Derechos Humanos (ACNUDH). 
En el ámbito interno, el Instituto Nacional de Derechos Humanos (INDH) ha denunciado el actuar abusivo de Carabineros y de las Fuerzas Armadas desde el inicio del Estado de Excepción constitucional. En efecto, el INDH informa que hasta el día 19 de marzo de $2020^{147}$ ha interpuesto 1.465 acciones judiciales ${ }^{148}$, dentro de las cuales se han presentado querellas en favor de 1805 personas $^{149}$.

En el mencionado reporte se indica que según la información recabada por el INDH, existirían un total de 3.838 personas heridas en el contexto de la protesta social ${ }^{150}$ advirtiendo que esa cifra no representa el universo total de personas heridas, sino solo los casos observados o constatados, lo que "...significa que la cantidad total de personas heridas por acción de agentes del Estado puede ser mayor a la reportada por el Instituto". La mayoría de las heridas han sido causadas por perdigones que lesionaron a 1.687 personas, mientras que 1.411 fueron heridas por golpes de agentes, 298 por lacrimógenas, 193 por balines, 53 por balas y en 196 casos no se ha podido detectar el origen de la lesión.

Por su parte, el MP en su Informe Estadístico Anual para el 2019151, indicaba que solo al 30 de noviembre había 5.558 víctimas del actuar de las Fuerzas Armadas y de Orden, de los cuales 834 son niños, niñas y adolescentes ${ }^{152}$. Casi un tercio de los heridos lo fue por arma de fuego (1.938 personas). El desglose de los delitos investigados por la fiscalía arroja 4.158 apremios ilegítimos, en 134 casos hubo torturas y más de 1.000 abusos contra particulares. Los desnudamientos y violencia sexual ocupan un lugar significativo de las denuncias en contra de las policías y el ejército: hubo 192 desnudamientos, 58 abusos sexuales, 19 amenazas de delitos sexuales y 9 violaciones o abusos sexuales agravados. Asimismo, el ente persecutor informó que en el contexto de la revuelta habían fallecido 31 personas, indicando que 4 de ellas habían sido víctimas de agentes del Estado y que 2 habían fallecido bajo su custodia, precisamente en comisarías. ${ }^{153}$ No obstante las altas cifras indicadas, el número de imputados formalizados en este tipo de delitos a la fecha de dicho Informe Estadístico asciende tan solo a 38 funcionarios ${ }^{154}$.

147 Reporte en https://www.indh.cl/bb/wp-content/uploads/2020/04/Reporte-INDH-19-de-marzo-de-2020.pdf

148 De ellas, 1.432 son querellas y 24 acciones de amparo constitucional y/o amparos ante los juzgados de garantías. La mayoría de los delitos querellados son gravísimos para cualquier país que se pretenda democrático. Si bien han sido catalogados por las autoridades políticas como "hechos aislados" o "incumplimiento de protocolos": el 74\% de las querellas interpuestas por el INDH corresponden a torturas y tratos crueles (1083 casos), mientras que la violencia sexual alcanza 203 casos que corresponden al 14\% de querellas. Más grave aún, existen 6 querellas por homicidio y 23 por el mismo delito en carácter de frustrado.

1491071 hombres, 364 mujeres y 278 niñas, niños y/o adolescentes. Dentro de ellas se cuentan 20 personas LGTBIQ, 13 con discapacidad, 8 migrantes y 7 pertenecientes a algún pueblo originario.

150 El $7 \%$ de los heridos son niñas y niños, el $12 \%$ mujeres adultas y el $81 \%$ hombres adultos.

151 Boletín Estadístico 2019 del Ministerio Público. División de Estudios de la Fiscalía Nacional. Disponible en http://www. fiscaliadechile.cl/Fiscalia/sala_prensa/noticias_det.do?id=17287

152 La institución más denunciada es Carabineros, con 4.170 víctimas en manos de sus funcionarios. Le sigue el Ejército, con 244 denuncias, la Policía de Investigaciones con 96, la Armada con 27 y otras instituciones con 15.

153 A este respecto se debe destacar, que los espacios de represión y violencia no fueron solo las calles. Según la información proporcionada por el MP, si bien en 3.798 casos los delitos de los agentes estatales fueron cometidos en la vía pública, se destaca que en 582 casos los hechos ocurrieron en comisarías, brigadas o cuarteles militares, 202 en los carros policiales, 79 personas fueron víctimas en el comercio y 72 en sus propios domicilios.

154 Ídem. p. 21. 
Cifras más actualizadas fueron entregadas en la cuenta pública del fiscal nacional del Ministerio Público de fecha 23 de abril de 2020, donde se precisó que las denuncias por delitos relacionados a violación a los derechos humanos se elevó a cerca de 6.900, sin embargo, no se entregó información oficial acerca del número de funcionarios formalizados hasta dicha fecha.

A pesar de la gravedad de los crímenes y delitos cometidos por funcionarios públicos hacia la población civil, la respuesta del sistema judicial hacia dichos ilícitos es bastante menos intensa que la observada en relación a los delitos cometidos por los manifestantes. La masividad de los ataques hacia la población civil, constatados tantos por instituciones públicas nacionales como por organismos internacionales de derechos humanos, dan cuenta de que los actos de violencia en contra de la población civil importan un crimen de lesa humanidad, en los términos que establece la Ley №20.357 que tipifica Crímenes de Lesa Humanidad, Genocidio y Crímenes de Guerra. Esta normativa establece dos requisitos copulativos: " $1^{\circ}$ Que el acto sea cometido como parte de un ataque generalizado o sistemático contra una población civil” y, en segundo lugar, que este ataque "responda a una política del Estado o de sus agentes; de grupos armados organizados que, bajo la dirección de un mando responsable, ejerzan sobre algún territorio un control tal que les permita realizar operaciones militares, o de grupos organizados que detenten un poder de hecho tal que favorezca la impunidad de sus actos" (art. 1으), entendiéndose el ataque generalizado como “...un mismo acto o varios actos simultáneos o inmediatamente sucesivos, que afectan o son dirigidos a un número considerable de personas" (art. $2^{\circ}$ ). La Corte Suprema de Chile, considerando la jurisprudencia de Tribunales y organismos internacionales, ha sostenido que hoy ésta es consistente en considerar “...como elementos típicos del crimen contra la humanidad - en lo que aquí interesa-, el que las acciones que los constituyen sean parte de un ataque generalizado o sistemático contra una población civil, y el conocimiento de dicho ataque por el agente"155.

En tales circunstancias es del todo claro que, tras los reportes tanto de organismos internacionales ya citados, así como por los reportes y cifras entregados por el INDH en cuanto al número de lesionados, muertos, abusos sexuales, torturas y tratos degradantes ejecutados por miembros de las Fuerzas Armadas y de Seguridad en contra de manifestantes y en general en contra la población civil - una vez decretado el Estado de Emergencia constitucional por parte del Gobierno- han traspasado el límite legalmente permitido en el monopolio del uso de la fuerza en la contención de las movilizaciones, marchas y actos de protesta desarrollados por la ciudadanía a partir del 18 de octubre de 2019.

\section{La emergencia de redes y colectivos impulsando la judicialización protectora en Wallmapu}

Ante la violencia policiaca en Wallmapu, diferentes personas ligadas al ámbito profesional jurídico, psicosocial y periodístico se autoconvocaron o agruparon espontáneamente a fin de contribuir a

155 Sentencia de la Corte Suprema causa rol № 25.657-2014 de fecha 11 de mayo de 2015. En el mismo sentido, SCS rol N 21.177-14 de 10 de noviembre de 2014, rol ํ2 2931-14 de 13 de noviembre de 2014, rol № 11.983-14 de 23 de diciembre de 2014. 
velar por la eficacia de las garantías civiles en los procedimientos policiales y judiciales. Habitual presencia en comisarías tenían ABOFEM (Asociación de abogadas feministas), Ampara tus Derechos (Colectivo de abogadas y abogados que participen de distintas organizaciones como Defensa de Clase Trabajadora (DECLAT), CIDSUR además de abogados y abogadas conscientes y jóvenes licenciados y licenciadas de Derecho de la Universidad Católica de Temuco) y Las Violetas (colectivo de psicólogas y trabajadoras sociales), quienes exigían a Carabineros las listas de detenidos, conocer el paradero de estos, la situación procesal en que quedarían y la materialización del derecho de los detenidos a recibir visitas, abrigo y alimentos, etc.

Una importante labor de educación jurídica desinstitucionalizada tenía lugar en las puertas mismas de las comisarías, donde los profesionales abogados, psicólogos y trabajadores sociales explicaban a familiares de los detenidos —en su mayoría primerizos - los alcances jurídicos de las situaciones detectadas y los eventuales cursos de acción. Prensa independiente procuraba transmitir la situación represiva ante el cerco comunicacional hegemónico, como los profesionales de Radio Kurruf que muchas veces se amanecían reporteando en marchas y comisarías.

Estas espontáneas formas de organización civil, convivían y colaboraban con las instituciones estatales encargadas de velar por la situación de los detenidos, como son la Defensoría Penal Pública y el Instituto Nacional de Derechos humanos. La información acerca de las personas detenidas, su estado de salud y condiciones de la aprehensión, eran compartidas y circulaban recíprocamente a través de grupos creados en redes sociales. De esta manera, los profesionales institucionales podían abocarse a situaciones donde su presencia — de por sí, inhibitoria frente a excesos policiales - podía resultar más trascendente. Destacamos estas situaciones porque constituyen instancias que ponen de manifiesto no solo los tejidos sociales civiles que emergen ante la represión, sino las coordinaciones con las instituciones estatales encargadas de velar por los DD.HH., matizando la habitual discusión que se plantea en el seno de los movimientos sociales acerca de la acción social institucional y desintitucionalizada.

Una de las situaciones más gráficas de la eficacia de este tipo de coordinaciones viene dada por la reunión que sostuvieron abogadas de estos colectivos civiles con el Juez Presidente del Tribunal de Garantía de Temuco, a partir de la cual nació una vía de comunicación más expedita que permitía denunciar con rapidez las violaciones a derechos fundamentales en Wallmapu.

\section{La ineficaz judicialización protectora en la Región de La Araucanía}

En el ámbito regional, el INDH ha interpuesto en La Araucanía 159 querellas por igual número de víctimas entre el 19 de octubre de 2019 y el 22 de marzo de 2020 por diversos delitos cometidos por funcionarios públicos, desde lesiones graves gravísimas hasta apremios ilegítimos o tratos degradantes. Hasta la fecha no existen imputados formalizados en ninguna de estas investigaciones. ${ }^{156}$

156 Información proporcionada por la Sede Regional Araucanía del Instituto Nacional de Derechos Humanos, Marzo 2020. 
En cuanto a las acciones constitucionales de amparo, el INDH ha interpuesto cinco recursos de amparo relacionados con abusos de funcionarios estatales hacia manifestantes del Estallido Social en la Novena Región, de los cuales cuatro fueron acogidos por la Corte de Apelaciones de Temuco $^{157}$, en tanto 1 de ellos fue rechazado ${ }^{158}$. Cada uno de estos fallos fueron confirmados posteriormente por la Excelentísima Corte Suprema o bien lisa y llanamente no fueron apeladas por las respectivas instituciones públicas.

De los amparos acogidos, llama la atención que 3 de estos datan del inicio de las protestas ciudadanas: el 20 de octubre de 2019 en Temuco, el 24 de octubre en la ciudad de Carahue y el 28 de octubre nuevamente en la ciudad de Temuco, con ocasión de una marcha convocada por personas discapacitadas. En cada uno de ellos, la Corte acoge los respectivos recursos y ordena al "Director General de Carabineros, Jefe de la IX Zona Araucanía, don Carlos González Gallegos, deber instruir a los funcionarios de Carabineros bajo su mando, la obligación de dar estricto cumplimiento a lo dispuesto en los protocolos institucionales de Carabineros sobre uso de la fuerza y de los dispositivos utilizados para controlar los desórdenes públicos".

Sin embargo, las situaciones de abusos policiales continuaron repitiéndose durante los meses que se mantuvieron activas las diversas manifestaciones sociales durante el año 2019 y comienzos del año 2020.

Un caso paradójico lo encontramos en el recurso de protección interpuesto por la Universidad Católica de Temuco y la Universidad de la Frontera en contra de Carabineros de Chile ${ }^{159}$ por la utilización desproporcionada de armamento menos letales en contra de manifestantes. En dicho recurso, la Corte de Temuco acogió con fecha 14 de noviembre una orden de no innovar "en cuanto se ordena a Carabineros la suspensión inmediata del uso de escopetas antidisturbios en el contexto de manifestaciones pacíficas que se desarrollen en la región, durante la tramitación del recurso de protección" todo esto en el contexto de las graves y masivas denuncias de mutilaciones oculares a manifestantes mediante el uso de dichas armas.

Pese a ello, y solo a modo ejemplar, el mismo día 14 de noviembre, mientras se desarrollaba una manifestación en conmemoración por el primer aniversario de la muerte de Camilo Catrillanca Marín, el joven de iniciales O.E.P.R. perdió uno de sus globos oculares producto del disparo de funcionarios de Carabineros, razón por la cual el INDH interpuso la respectiva querella criminal ante el Juzgado de Garantía de Temuco ${ }^{160}$. Lo descrito viene a configurar un escenario desolador para la ciudadanía, en cuanto aún en aquellos casos donde una Corte de Justicia le ordena a la policía abstenerse de ejecutar determinados actos para la protección de la libertad y seguridad de los manifestantes, Carabineros de Chile lisa y llanamente desoye lo ordenado sin que hasta la fecha exista alguna sanción, sumario o una mínima rendición de cuentas de las razones para no acatar las resoluciones de un Tribunal.

157 Información proporcionada por la Sede Regional Araucanía del Instituto Nacional de Derechos Humanos, Marzo 2020. 157 Rol 1952019; 216-2019; 224-2019 y 237-2019, todos de la Corte de Apelaciones de Temuco

158 1 241-2019 de la Corte de Apelaciones de Temuco.

159 Rol N 17.653 - 2019 de la Corte de Apelaciones de Temuco.

160 Causa RIT 11879-2019 del Juzgado de Garantía de Temuco. 
Lo anterior es ciertamente preocupante si consideramos que los Tribunales de Justicia son los órganos del Estado mandatados constitucionalmente para el resguardo de los derechos fundamentales de los ciudadanos ante las infracciones del poder público, pero que sin embargo no han logrado poner freno a los atropellos a la libertad ambulatoria y a la seguridad individual de los ciudadanos, a pesar de haber sido constatada su infracción y ordenado el restablecimiento del derecho amagado como ha ocurrido con los recursos de amparo interpuestos por el INDH.

Esta ineficacia de FACTO de las resoluciones judiciales que ordena en estos casos a Carabineros de Chile a sujetar su actuar a la Constitución, las leyes y a sus propios protocolos de actuación, transforma los actos jurisdiccionales en meras declaraciones de buenas intenciones que socavan la institucionalidad vigente y reafirman el ambiente de impunidad, el temor y la desconfianza hacia la real capacidad de los Tribunales de Justicia para salvaguardar y dar efectiva protección a la población civil.

Por su parte, en la Cuenta Pública 2019, el fiscal regional de La Araucanía informó que solo entre el 19 de octubre y el 06 de diciembre, habían ingresado 381 causas por "eventuales" delitos cometidos por agentes del Estado ${ }^{161}$. De estas causas, el $64 \%$ se relacionancon el delito de abusos contra particulares, $26 \%$ a apremios ilegítimos y existen 7 casos, que representan el $2 \%$, en que agentes estatales provocaron lesiones graves gravísimas: traumas oculares por perdigones o bombas lacrimógenas. Y aunque el número de causas ingresadas a la Unidad de DD.HH. encargada de investigar la violencia institucional- se incrementó en un 49\% respecto del año anterior, el Ministerio Público no tomó ninguna medida especial para asegurar una persecución penal más eficaz, lo que ha traído como consecuencia que a pesar de las gravosas mutilaciones producidas a los ciudadanos hasta la fecha no existan formalizados por estas causas. Lo anterior devela la falta de urgencia de parte de la fiscalía de La Araucanía para llevar a la justicia a agentes del Estado que come- tan delitos constitutivos de violaciones de derechos humanos.

La violación del principio de objetividad, al brindar un tratamiento diametralmente distinto a imputados uniformados y civiles, es patente y se reafirma con el propio discurso del fiscal regional respecto a la violencia institucional cuando indica que: "Creemos que este tipo de causas necesitan especialmente soluciones definitivas de carácter judicial: sentencias, salidas alternativas o incluso sobreseimientos definitivos, porque también hay un número importante de casos en que la investigación puede establecer que el uso de la fuerza es legítimo. Se hace necesaria una respuesta del sistema de justicia que establezca fehacientemente qué pasó, necesidad que no solo es de las víctimas, sino también de quienes son imputados de tales hechos."

\section{Una justicia ciega a la Mutilación oculares}

Entre las víctimas de la violencia estatal, particular notoriedad han tenido las lesiones de globos oculares, tanto por las secuelas que tales lesiones reportan para las víctimas —en su gran mayoría

161 Merece la pena resaltar el adjetivo empleado por el Fiscal Regional, que demuestra una pulcra observancia del principio de objetividad, pero que párrafos más arriba en su cuenta pública, no había tenido la sutileza de emplear en relación a los delitos imputados a manifestantes. 
jóvenes que han visto alterada profundamente sus proyectos de vida-, así como la carga simbólica que implica cegar a quien denuncia una realidad social injusta. La masividad de estos delitos es manifiesta: 405 casos al 15 de enero de 2020, una verdadera "emergencia sanitaria" según el presidente de la Sociedad Chilena de Oftalmología ${ }^{162}$.

La masividad y sistematicidad de tales lesiones en los manifestantes ha abierto una importante discusión a nivel nacional en relación al uso indiscriminado de las armas menos letales utilizadas por Carabineros de Chile. En nuestro país el uso de la fuerza por parte de la policía no está regulado en la ley, sino que en circulares, decretos y protocolos, es decir, normas de inferior rango que una ley común y que, por tanto, no gozan de la discusión necesaria a nivel parlamentario que permita un verdadero control de su contenido ${ }^{163}$.

En relación al uso de escopetas antidisturbio (consideradas por Carabineros como armas no letales) la circular realiza una clara distinción con las armas potencialmente letales, las cuales restringe expresamente para ser utilizadas en circunstancias excepcionales que supongan la existencia de un peligro inminente de muerte o lesiones graves sea para el Carabinero o para cualquier otra persona ${ }^{164}$. El protocolo indica que: "su empleo deberá ser consecuencia de una aplicación necesaria, legal, proporcional y progresiva de los medios y cuando el efecto de otros elementos tales como agua, gases y otros resulten insuficientes, o el nivel de agresividad haga aconsejable su utilización un mal mayor donde esté en riesgo la integridad física de los transeúntes, manifestantes o carabineros."165

La permisividad que el protocolo otorga a Carabineros de Chile en el uso de armas de fuego altamente dañosas en contra de manifestantes, es ostensible. Su utilización queda al arbitrio del respectivo funcionario en cuanto considere que los otros elementos disuasivos no sean suficientes para poner término a la manifestación, o bien cuando el policía tirador entienda que se encuentra en riesgo la integridad física de carabineros o de cualquier persona. Así, el protocolo permitiría su utilización en contra de manifestantes desarmados que utilicen piedras en contra de carabineros o bien en contra de aquellas personas que se encuentren manifestándose pacíficamente sin autorización de la autoridad tras haber sido dispersados por el carro lanza aguas y lanza gases. En cualquiera de estos casos, la desproporción se torna evidente, pero que a la luz del protocolo y del respaldo recibido de parte de la autoridad civil y militar ha implicado una verdadera "catástrofe de derechos humanos" ${ }^{\prime 166}$.

162 Declaración de Dennis Cortés, Presidente de la Sociedad de Oftalmología en la Comisión de DD.HH. del Senado.

163 La actual normativa que regula el uso de la fuerza y, en particular, el uso de armas de fuego en la represión de manifestaciones sociales son: i) Decreto N 1364 de 2018 redactado por el Ministerio del Interior, es decir, suscrito por el anterior Ministro Andrés Chadwick cuyo cargo debió abandonar al ser aprobada la acusación constitucional en su contra precisamente por omitir adoptar medidas para detener violaciones sistemáticas a los derechos humanos; y ii) la circular $\mathrm{N}^{\circ} 1.832$ y la Orden General ํํ 2635 de 2019 , ambas redactadas por la propia institución policial cuestionada y suscritos por el actual General Director de Carabineros Mario Rozas. Mismo oficial que en su discurso dirigida a personal de la Escuela de Suboficiales de Carabineros en noviembre de 2019, manifestó su apoyo a los funcionarios expresando que no daría a nadie de baja ni aunque fuese obligado

https://radio.uchile.cl/2019/11/13/general-director-de-carabineros-a-nadie-voy-a-dar-de-baja-aunque-me-obliguen-no-lo-voy-ahacer/

164 Orden General ํ 2635 de 2019.

165 Idem.

166 Dr. Enrique Morales, Entrevista para reportaje 'It's Mutilation': The Police in Chile Are Blinding Protesters New York Times, reportaje audiovisual del diario estadounidense The New York Times que denunció las mutilaciones oculares durante el "Estallido Social” y que 
La novena región no ha sido ajena a dicha realidad. A la fecha se contabilizan 7 personas con lesiones o traumas oculares, dos de ellas con pérdida o estallido ocular. En la ciudad de Temuco, con fecha 19 de octubre de 2019 se reportó el primer caso de estallido ocular del país. El joven Luis Jimenez Caamaño, estudiante de Trabajo social, fue gravemente herido producto del disparo efectuado por el comisario de la $1^{\circ}$ Comisaría de Fuerzas Especiales de Temuco, quien reconoció en el respectivo parte policial haber efectuado los disparos en contra de los manifestantes. Pese a la querella interpuesta ${ }^{167}$ y a los meses desde el inicio de la investigación, tanto en esta como en cada una de estas investigaciones no existen formalizados.

El Centro de Investigación y Defensa Sur ha interpuesto dos querellas criminales, en representación de Luis Jiménez Caamaño ${ }^{168}$ y Camilo Olivares Moreno ${ }^{169}$, ambos lesionados oculares durante los primeros días del Estallido Social, invocando la Ley 20.357 que tipifica Crímenes de lesa humanidad y Genocidio y Crímenes de Guerra, calificando los hechos como lesiones gravísimas en carácter de lesa humanidad, con el objeto de que los crímenes sean investigados y sancionados de acuerdo a la gravedad de los mismos.

Vale destacar que tanto el INDH, así como el MP han calificado los hechos hasta esta etapa de la investigación únicamente como delitos comunes, aplicando solo las normas referentes a lesiones del Código Penal. En consecuencia, cada una de tales investigaciones se encuentran rotuladas bajo investigación por delitos comunes, pese a la existencia de los informes de DD.HH. ya citados y que han calificado tales hechos como graves violaciones a los derechos fundamentales de las personas.

\section{Simulacro de fusilamiento}

Otro de los hechos que suscitó interés y desconcierto en la región durante la vigencia del Estado de Excepción constitucional fue el ocurrido el 22 de octubre de 2019, a los jóvenes de iniciales R.G.Q., y C.C.M., ambos mayores de edad, cuando retornaban desde las manifestaciones a sus hogares. A pesar de que se encontraban caminando tranquilos y sin realizar ningún acto de protesta, fueron detenidos y maltratados por militares, quienes los botaron al suelo, aplastaron sus cabezas y les colocaron amarras plásticas en las muñecas. Posteriormente, los funcionarios del ejército les pegaron con la punta de sus fusiles y les apuntaron en la cabeza, para subirlos a un vehículo militar, diciéndoles que los llevarían a una comisaría. Sin embargo, durante el trayecto les señalaron que los llevarían al cuartel para "ponerlos en la cama elástica con electricidad para ver cuánto aguantarían". Finalmente fueron conducidos al sector del Cerro Mariposa donde los bajaron del vehículo, los arrodillaron mirando hacia una pandereta, haciéndoles creer que los fusilarían.

que se alzó como ganador en competencia patrocinada por World Press Photo 2020.

167 RUC № 1901134991-1, RIT 10579-2019 del Juzgado de Garantía de Temuco.

168 Idem.

169 RUC 1910053095-6; RIT 10505-2019 del Juzgado de Garantía de Temuco. 


\section{Capítulo 5. Página 111}

Finalmente, les quitaron las amarras, los patearon y les dijeron que debían correr por donde venían, advirtiéndoles que si retrocedían los iban a matar, cargando las armas y riendo mientras ambas víctimas corrían.

Llama la atención en el presente caso, no solo la brutalidad y la absoluta impunidad que hasta la fecha gozan los autores del caso, sino además el conocimiento demostrado por los funcionarios militares en relación a las técnicas de tortura, como es la colocación de corriente y la simulación de un fusilamiento o ejecución extrajudicial, lo que rememora de forma inmediata los acontecimientos vividos en Chile durante la dictadura militar, y lo que permite avizorar que tales prácticas, tras 47 años del golpe militar, continúan siendo perfectamente conocidas por los funcionarios militares que sin lugar a dudas no vivieron dicho periodo histórico.

Respecto de este caso, CIDSUR interpuso la respectiva querella criminal invocando la Ley 20.357 que tipifica Crímenes de lesa humanidad y Genocidio y Crímenes de Guerra. Sin embargo, pese al tiempo transcurrido desde estos sucesos, a la identificación precisa de los vehículos militares y funcionarios que desarrollaron labores de custodia el día de los hechos, se ve aún lejana la posibilidad de formalizar cargos en contra de los responsables.

\section{Traslación de la excepción en Wallmapu al territorio nacional: constante para el mapuche, novedad para el chileno}

Con el respaldo irrestricto de los gobiernos concertacionistas en concomitancia con el Poder Judicial, desde el fin de la dictadura hasta la fecha y, en particular, a partir del "estallido mapuche" de Lumaco en 1997, las comunidades mapuche han sido el escenario privilegiado de violentas operaciones policiales. Un Estado de Excepción permanente, aunque no declarado, se ha instaurado en estas comunidades en nombre de la lucha en contra del terrorismo y de la violencia rural que se ha visto judicialmente respaldado mediante la invocación de leyes de excepción como la Ley sobre Conductas Terroristas - hacia comuneros acusados de participar en delitos asociados a la reivindicación territorial. Producto de esta represión, son centenares los mapuche que han sido heridos con total impunidad por balines y perdigones, mientras otros tantos han debido soportar largas privaciones de libertad producto de la invocación de dichas leyes, las más gravosas del ordenamiento jurídico nacional ${ }^{170}$.

Esta política criminal, por tanto, ha comprendido dos fases o dinámicas que se desenvuelven de forma paralela y simbiótica.

Por una parte, las comunidades movilizadas han sido criminalizadas mediante la persecución penal de sus dirigentes, el allanamiento de sus viviendas, el desalojo de los predios ocupados y la detención y encarcelamiento de sus miembros gracias a la utilización del nuevo proceso penal instaurado en la Región de La Araucanía desde el año 2001, mismo año en que comienza a ser invocada la Ley Antiterrorista en contra de miembros del Pueblo Mapuche.

\footnotetext{
170 Ver Centro de Investigación y Defensa Sur (2019). “Crímenes y montaje como política. Indígena: el caso Huracán, e comando Jungla y los efectos en niños, niñas y Adolescentes mapuche”. Anuario del Conflicto Social. No. 9. Disponible en https://revistes.ub.edu/index.php/ACS/article/view/30589/30776
} 
Seguidamente, y en un segundo nivel, los delitos cometidos por los agentes del Estado en la ejecución de dicha política de persecución penal son ampliamente tolerados por el sistema judicial, lo que refuerza el ambiente de indefensión y desconfianza hacia la institucionalidad de parte de los miembros de tales comunidades. Sin duda el caso emblemático al efecto es el del adolescente Alex Lemun Saavedra, quien fuera abatido por el disparo efectuado por el entonces mayor de Carabineros Marco Treuer, el que impactó en su cabeza y le provocó la muerte el 12 de noviembre de 2002. Luego de presentadas las acciones legales, y pese al enorme cúmulo de antecedentes en contra del autor de los disparos, la causa fue sobreseída por la justicia militar el año 2004. El Estado de Chile fue incapaz de sancionar al oficial de Carabineros que dio muerte a un niño de 17 años mientras desalojaba una comunidad desde el predio reivindicado por los mapuche a la forestal Mininco.

Frente a la denegación de justicia en la muerte del adolescente Lemun, el caso fue llevado ante la Comisión Interamericana de Derechos Humanos (CIDH), la que el 2017 estableció que el Estado de Chile era responsable por la violación del derecho a la vida, a la integridad personal y a la igualdad y no discriminación, así como a las garantías judiciales y protección judicial ${ }^{171}$. Solo de este modo, el caso fue reabierto, y trasladado su conocimiento a la jurisdicción civil, donde actualmente el oficial en retiro de Carabineros se encuentra acusado por el delito de homicidio ${ }^{172}$.

Por otra parte, la Corte Interamericana de Derechos Humanos condenó al Estado chileno en el año 2014 en denominado "Caso Lonkos y otros dirigentes mapuche" por irregularidades en el uso de la Ley Antiterrorista contra líderes mapuche en los 3 casos ya reseñados ${ }^{173}$. El 26 de abril del 2019 la Corte Suprema dio cumplimiento a la medida reparatoria hacia las víctimas solicitada por la Corte IDH, dejando sin efecto las condenas dictadas entre 2003 y 2004 por los Tribunales en Chile. El fallo internacional y la ratificación de la Corte Suprema pone en el centro a las víctimas injustamente condenadas por delitos calificados como terrorismo y exponen las negligencias y faltas discriminatorias de los operadores del Sistema de Justicia (incluyendo jueces, persecutores, Cortes de Apelaciones, Corte Suprema, así como el Gobiernos de Chile que actuó como querellantes junto aforestal Mininco, a través del Ministerio del Interior, intendencias regionales y gobernaciones provinciales).

Así, a pesar de las condenas y requerimientos internacionales derivados de la violencia estatal en contra del Pueblo Mapuche, el uso desmedido de la fuerza por personal a cargo del orden público no ha cesado. Al contrario, esta desproporción en el uso de la fuerza se ha incrementado y expandido al resto del territorio nacional con ocasión del Estallido Social de octubre de 2019.

171 Informe 31/17 en caso $N^{\circ} 12.880$ “Edmundo Lemun Saavedra Vs. Chile” de la Comisión Interamericana de Derechos Humanos.

172 Causa RIT 4-2020 del tribunal Oral en lo Penal de Angol. Actualmente se encuentra agendada audiencia de juicio oral para el día 21 de enero de 2021.

173 Corte Interamericana de Derechos Humanos. Caso Norín Catrimán y Otros (dirigentes, miembros y activistas del Pueblo Indígena Mapuche) vs. Chile. Sentencia de 29 de mayo de 2014. (Fondo, Reparaciones y Costas). 


\section{Capítulo 5. Página 113}

Sin duda, la capacitación y el actuar de Carabineros de Chile no se ha ajustado a estándares de DD.HH. en el uso legal de la fuerza, situación que es conocida durante décadas por los comuneros mapuche que reivindican sus derechos territoriales.

Del mismo modo, la invocación de legislaciones especiales — como la Ley de Seguridad del Estado- o bien las reformas legales que han buscado el aumento de penas para delitos comunes - como la Ley Antisaqueo- o la tipificación de conductas anteriormente no sancionadas - como el tipo penal que sanciona el denominado "el que baila pasa" - son realidades que tienden a seguir los mismos patrones de represión hacia la protesta mapuche y que ahora se expande contra el ciudadano no mapuche que manifiesta su disconformidad con el modelo político y de desarrollo económico establecido. En el mismo sentido, las acciones legales emprendidas por las víctimas de la represión estatal han sido del todo insuficientes y no han logrado la protección adecuada a los derechos fundamentales de las personas.

\section{“No eran los mapuche los que mentían, era la tele"}

Desde octubre del año 2019 la sociedad civil ha sido víctima de una amplia gama de graves violaciones a sus derechos humanos por parte de agentes del Estado, siendo la política represiva, de la violencia, el miedo, la militarización y la criminalización de los manifestantes, la forma elegida por el Gobierno para manejar un conflicto social de profundas raíces históricas.

Las consecuencias de esta violencia represiva son transversalmente condenadas en el derecho internacional de los derechos humanos, en el que se reconoce ampliamente la prohibición absoluta de someter a las personas a cualquier acto de tortura u otros tratos crueles, inhumanos o degradantes. Asimismo, se establece la obligación para los estados de investigar, sancionar y reparar este tipo de actos. Por esta razón es que CIDSUR, durante la última década, ha complementado su labor, documentando a través de pericias psicológicas y sociales los efectos de violaciones a los derechos humanos contra personas mapuche víctimas de violencia policial, acusadas de delitos comunes o imputadas por delitos de terrorismo, la mayoría de ellos absueltos luego de largas prisiones preventivas. Estas pericias psicológicas basadas en los lineamientos del Protocolo de Estambul ${ }^{174}$, documentan los abusos que han vivido niños, niñas, adolescentes y adultos mapuche violentados y criminalizados por aplicación de la Ley Antiterrorista, entre otras figuras penales. El propósito ha sido articular tales experiencias en informes psico-forenses, que se llevan como evidencia a los sistemas de justicia nacionales e internacionales, para explicar los efectos de experiencias traumáticas asociadas a la violencia de estado y con el fin de buscar justicia y reparación a las víctimas (Vargas, 2017). Las experiencias traumáticas documentadas abarcan hechos tales como detenciones violentas, allanamientos nocturnos a los hogares, secuestros, golpizas, torturas, confesiones forzadas y lesiones graves de las que han sido víctimas niños, adultos, ancianos e incluso la muerte de jóvenes mapuche.

174 Organización de las Naciones Unidas (2004) Protocolo de Estambul es una herramienta forense internacional que guía la constatación médica, psicológica y legal en víctimas de tortura, tratos crueles inhumanos y degradantes. Es un procedimiento que se ajusta a los requerimientos de organismos internacionales de protección a los derechos humanos y puede ser presentado como evidencia legal ante tribunales nacionales e internacionales. 
Poco menos de un año antes del Estallido Social, el joven mapuche Camilo Catrillanca había sido asesinado al interior de su comunidad, en la zona de Ercilla, Región de La Araucanía, por un comando de policía militarizada provisto con armamento de guerra que, en un primer momento, desplegó una red de mentiras para encubrir las reales circunstancias del hecho. Un año antes de este crimen, el año 2017, tuvo lugar la mediática Operación Huracán y sus televisados operativos para detener a ocho personas, incluidas seis autoridades tradicionales y líderes mapuche, acusados de perpetrar atentados terroristas por medio de una asociación ilícita. Esta asociación habría sido descubierta por una operación de inteligencia que intervino las aplicaciones telefónicas de los imputados. Semanas después se conocieron las pericias que evidenciaron la implantación de las pruebas por funcionarios policiales y, como consecuencia, la falsedad de las imputaciones orquestadas desde los altos mandos policiales y autoridades de Gobierno.

Estos eventos se encontraban aún en la memoria nacional al ocurrir el Estallido del 18 de octubre y la brutal represión desatada contra ese enemigo poderoso e implacable que señalaba Piñera. Las convergencias e intersecciones entre las demandas del Pueblo Mapuche y las que estallan desde el pueblo chileno son múltiples y poseen también muchas aristas. Sin embargo, la represión y la judicialización, con todos sus efectos se hicieron sentir con fuerza entre los chilenos, confirmando las denuncias que por décadas viene realizando el Pueblo Mapuche respecto a las violaciones impunes de sus derechos humanos por agentes del Estado, como forma de acallar sus demandas.

Es evidente que las familias mapuche, comunidades y grupo cultural, es decir, los miembros del Pueblo Mapuche, han sido gravemente afectados durante las últimas dos décadas en los sistemas de justicia chileno por el trato de terrorista, con secuelas claramente sostenidas en el tiempo. Las detenciones violentas y procedimientos judiciales han vulnerado los derechos fundamentales de las personas, afectando la salud física y mental de los integrantes de las familias y de las comunidades por el sufrimiento al que han sido expuestos. Además, se ha estigmatizado la demanda política y territorial de los pueblos indígenas como terrorismo. Las consecuencias se mantienen a nivel individual y familiar con alteraciones en los proyectos de vida de la persona, familia y comunidades afectadas por los abusos del Estado (Vargas, 2017). El trauma individual y familiar deviene en un trauma psicosocial, intergeneracional y cultural, caracterizado por la violencia, la amenaza y estigmatización que esta ley ejerce en los mapuche como grupo cultural y miembros de un pueblo indígena que solicita reconocimiento de derechos colectivos ya ratificados por el Estado de Chile (Vargas, 2017).

Al reproducir, desde el 18 de octubre, esta política represiva y criminalizadora hacia el pueblo chileno, el Estado y sus instituciones judiciales van diluyendo su función de garantes de derecho, transformándose en la fuente de un terror, un desamparo y una indefensión frente al poder institucional, tal como lo ha venido haciendo con el Pueblo Mapuche. Con estas actuaciones, además de permitir procesos de retraumatización y revictimización en sus salas de audiencia, los órganos de justicia continúan amparando la impunidad con consecuencias de largo plazo en las víctimas y comunidades al negar la justicia y las garantías de reconocimiento y reparación de las víctimas. La impunidad provoca entonces doble daño psicosocial: no se reconoce el daño, y al no 
reconocer el daño, no se reconoce a la víctima como tal ${ }^{175}$.

Los aportes que la evidencia psicológica y médica pueden ofrecer en la efectiva investigación de las denuncias de presuntas torturas, y en litigios estratégicos elevados a los sistemas internacionales que resalta el derecho de las víctimas, enfatizando en la necesidad de abordar las distintas dimensiones del daño, desde el sufrimiento psíquico al daño psicosocial, entendiendo que la represión busca impactar en el individuo y en el tejido social de manera simultánea. Frente a esta urgencia social, que ha provocado una enorme cantidad de víctimas en pocas semanas, y en los meses subsiguientes, queda en evidencia la necesidad de asistencia especializada para los afectados, ya que de acuerdo a nuestra experiencia, estas situaciones requieren abordajes con enfoques reparatorios en el marco de las especificidades clínicas que contemplen el modo particular en que se documentan los efectos traumáticos derivados de graves violaciones de derechos humanos y la atención a sus consecuencias.

Cuando se niega la justicia, el sistema se vuelve "cómplice" de la infracción primaria y no solo se produce en su interior una victimización secundaria (institucionalizada), sino que se hace responsable por omisión en la investigación, lo cual incluye hasta la responsabilidad internacional del Estado por actos de sus funcionarios.

\section{Conclusiones}

La judicialización de la protesta social puede asumir diferentes formas: detenciones y prisiones preventivas masivas, creación de nuevos delitos o agravamiento de penas, interposición de querellas, recursos de protección y amparo ante la violencia policial, informes nacionales e internacionales de organismos especializados en DD.HH., etc. Esto muestra que el derecho es otro campo de batalla, en el que se libran luchas impulsadas por estrategias que buscan reprimir la protesta social o establecer un ámbito de protección en favor de los manifestantes. A la primera la hemos denominado judicialización represiva y a la segunda judicialización protectora o defensiva.

El número de formalizaciones y avances en las respectivas investigaciones penales por las graves violaciones a los derechos fundamentales de los manifestantes, a manos de funcionarios militares y de Carabineros, marcan una diferencia significativa con las investigaciones por hechos delictuales asociadas a las protestas sociales ejecutados por la sociedad civil, para lo cual basta con constatar las cifras de formalizaciones y condenas en uno y otro tipo de delitos. Esto hace patente que la judicialización represiva de la protesta social, presenta mayor eficacia que la judicialización protectora de la misma.

175 “1. Se entenderá por "víctimas" las personas que, individual o colectivamente, hayan sufrido daños, inclusive lesiones físicas o mentales, sufrimiento emocional, pérdida financiera o menoscabo sustancial de los derechos fundamentales, como consecuencia de acciones u omisiones que violen la legislación penal vigente en los Estados Miembros, incluida la que proscribe el abuso de poder." Asamblea General de Naciones Unidas (1985). Declaración sobre los principios fundamentales de justifica para las víctimas de delitos y del abuso de poder. Art. 1 
En un segundo nivel de análisis, estimamos que la tolerancia institucional de la violencia policial y militar más allá de lo legalmente permitido, busca la desmovilización de los manifestantes, aún de aquellos que lo hacen de forma pacífica, con el objeto de aplacar las manifestaciones no por la vía política, sino derechamente a través del uso de la violencia institucional e ilegítima, producto de una falta de respuesta de las autoridades al malestar ciudadano, que exige un cambio político y económico de mayor profundidad que el propuesto por la clase política y la clase militar. Creemos que esto devela una instrumentalización política de la justicia.

Desde el punto de vista de los efectos psicosociales, el proceso de descrédito y deslegitimación de la institucionalidad chilena en general y judicial, en particular, que existe en las comunidades mapuche como consecuencia de un comportamiento arbitrario, vulnerador y revictimizante, arriesga extenderse al resto de la población chilena, con los consecuente efectos que deslegitiman y horadadores de la democracia. Así, el aparato judicial cooptado como instrumento de control social, mantiene y reproduce la vulneración de los derechos de las víctimas, actuando como una instancia que profundiza y complejiza el sufrimiento de las víctimas de la violencia policial y política.

La instrumentalización política de la justicia es una situación que se ha experimentado durante décadas en Wallmapu. Mediante una sobrerreacción penal hacia hechos delictivos asociados a la protesta por la reivindicación territorial del Pueblo Mapuche, se impone un Estado de Excepción no declarado que conlleva, por una parte, allanamientos violentos, persecución de dirigentes e invocación de leyes de excepción; y por otra, una evidente tolerancia de parte del mundo político y judicial hacia la violencia desproporcionada e ilegal de parte de los agentes estatales encargados de ejecutar dicha política criminal. 


\section{Bibliografía}

AMNISTÍA INTERNACIONAL. (21 de Noviembre de 2019). Chile: Política deliberada para dañar a manifestantes apunta a responsabilidad de mando. Obtenido de Amnistí Internacional https://www.amnesty.org/es/latest/news/2019/11/chile-responsable-politica-deliberada-paradanar-manifestantes/

ALTO COMISIONADO PARA LOS DD.HH. DE LAS NACIONES UNIDAS. (2019). Informe sobre la Misión a Chile. Obtenido de Naciones https://www.ohchr.org/Documents/Countries/CL/Report_Chile_2019_SP.pdf

CIDSUR. (2019). Crímenes y Montaje como política indígenas: El caso Huracán, el Comando Jungla y los efectos en Niños, Niñas y Adolescentes Mapuche. Anuari del Conflicte Social, 47-90.

COMISIÓN INTERAMERICANA DE DERECHOS HUMANOS. (06 de Diciembre de 2019).

CIDH Condena el uso excesivo de la fuerza en el contexto de las protestas sociales en Chile, expresa su grave preocupación por el elevado número de denuncias y rechaza toda forma de violencia. Obtenido de CIDH: http://www.oas.org/es/cidh/prensa/comunica-dos/2019/317.asp

COMUNIDAD DE HISTORIA MAPUCHE (20015). Violencias coloniales en Wajmapu. Temuco: Ediciones Comunidad, de Historia Mapuche.

DECRETO № 843. Ministerio del Interior. Diario Oficial de la República de Chile, Santia go, Chile, 17 de junio de 2011

DIARIO OFICIAL DE LA REPÚBliCA DE CHILE. (2010). Constitución Política de la República. Santiago: Editorial Jurídica de Chile.

DIRECCIÓN DE ESTUDIOS DE LA CORTE SUPREMA (2020). “El Rol Del Poder Judicial En El Conocimiento de Las Acciones Judiciales Relacionadas Al Estallido Social." Santiago. Obtenido de: http://decs.pjud.cl/download/el-rol-del-poder-judicial-en-el-conoci- miento-de-las-accionesjudiciales-relacionadas-al-estallido-social/

EDITORIAL JURÍDICA DE CHILE(2020). Código Penal (Estudiante). Santiago: Editorial Jurídica De Chile.

GUTIÉRREZ DE PIÑERES BOTERO, C., CORONEL, E., y ANDRÉS PÉREZ, C. (2009). Revisión teórica del concepto de victimización secundaria. Liberabit, 15(1), 49-58.

HUMAN RIGHTS WATCH. (26 de Noviembre de 2019). Chile: Llamado urgente a una reforma policial tras las protestas. Obtenido de Human Rights Watch: https://www.hrw.org/ es/news/2019/11/26/chile-llamado-urgente-una-reforma-policial-tras-las-protestas

LEY N²1.208. Diario Oficial de la República de Chile, Santiago, Chile, 30 de enero 2020.

LEY № 12.972. Diario Oficial de la República de Chile, Santiago, Chile, sobre Seguridad del Estado. 06 de agosto de 1958.

PAIRICÁN, F. (2014). Malón. La rebelión del movimiento mapuche. 1990-2013. Santiago. Pehuen Editores.

VARGAS, R. (2017 Pewmas / Sueños de Justicia. Lonkos y dirigentes mapuche vs Chile en la Corte Interamericana: Testimonios y evidencia de los efectos psicosociales de la ley Antiterrorista. Chile, Santiago, LOM Ediciones 


\section{Capítulo 5. Página 118}

VILLEGAS, M. (2013). Estado de Excepción y antiterrorismo en Chile. Criminalización de la protesta social con especial referencia a los indígenas. Revista de Derecho Penal y Criminología. Año 3. N 6. Julio 2013. pp. 3-25.

\section{Cronología}

\begin{tabular}{|c|c|}
\hline Fecha & Acontecimiento \\
\hline 1 de enero de 2019 & $\begin{array}{l}\text { Ataques } \\
\text { incendia Lanco, y el ataque a Carabineros de punto fijo en } \\
\text { rios en LaCollipulli. } \\
\text { Araucanía }\end{array}$ \\
\hline 2 de enero de 2019 & 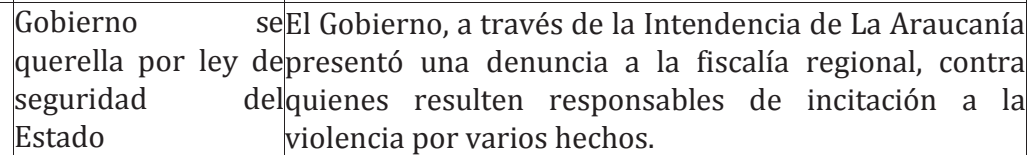 \\
\hline de enero de 2019 & $\begin{array}{l}\text { Gobierno impulsaLa policía civil aumentará dotación investigativa en la } \\
\text { mayor presencia dezona, tras últimos hechos de violencia. } \\
\text { efectivos de la PDI } \\
\text { en La Araucanía }\end{array}$ \\
\hline $\begin{array}{lll}10 \text { de enero de } \\
2019\end{array}$ & $\begin{array}{ll}\text { eDesalojo } & \text { de La sede se encontraba tomada por un grupo de } \\
\text { Municipio } & \text { de comuneros mapuche con varias demandas, entre ellas } \\
\text { Collipulli } & \text { el asesinato de Camilo Catrillanca. }\end{array}$ \\
\hline $\begin{array}{|lrl|}20 & \text { de } & \text { enero } \\
2019 & \end{array}$ & $\begin{array}{l}\text { elnstalación de mesaForestales, comunidades mapuche y CONADI buscan } \\
\text { por traspaso dedefinir las magnitudes de las demandas territoriales. } \\
\text { tierras }\end{array}$ \\
\hline $\begin{array}{l}14 \text { de mayo de } \\
2019\end{array}$ & \begin{tabular}{l|l} 
eAgenlegislativa & Presidente Piñera presenta la agenda legislativa \\
da & indígena en La Moneda. \\
indíg & \\
ena &
\end{tabular} \\
\hline $\begin{array}{lll}16 & \text { de } \\
2019 & & \end{array}$ & \begin{tabular}{|l|l} 
Sentencia & Corte Suprema deja sin efecto las condenas, siguiendo \\
Cas lo planteado por la Corte Interamericana de Derechos & \\
o Norín-Catrimán & Humanos.
\end{tabular} \\
\hline $\begin{array}{l}22 \text { de mayo de } \\
2019\end{array}$ & $\begin{array}{l}\text { eInicio de ConsultaEl Ministerio de Desarrollo Social y Familia inicia el } \\
\text { Indígena } \\
\text { proceso de Consulta Indígena que busca modificar } \\
\text { aspectos de la Ley 19.253 }\end{array}$ \\
\hline $\begin{array}{l}18 \text { de octubre } \\
2019\end{array}$ & $\begin{array}{l}\text { eInicio de Estallido o Miles de chilenos salen a las calles a manifestarse por } \\
\text { Revuelta Popular } \\
\begin{array}{ll}\text { un cambio profundo en las condiciones políticas, } \\
\text { económicas y sociales actuales. Presidente Piñera } \\
\text { decreta Estado de Excepción constitucional en las } \\
\text { provincias de Santiago, Chacabuco y dos comunas de la } \\
\text { Región Metropolitana. }\end{array}\end{array}$ \\
\hline
\end{tabular}




\section{Capitulo 5. Página 119}

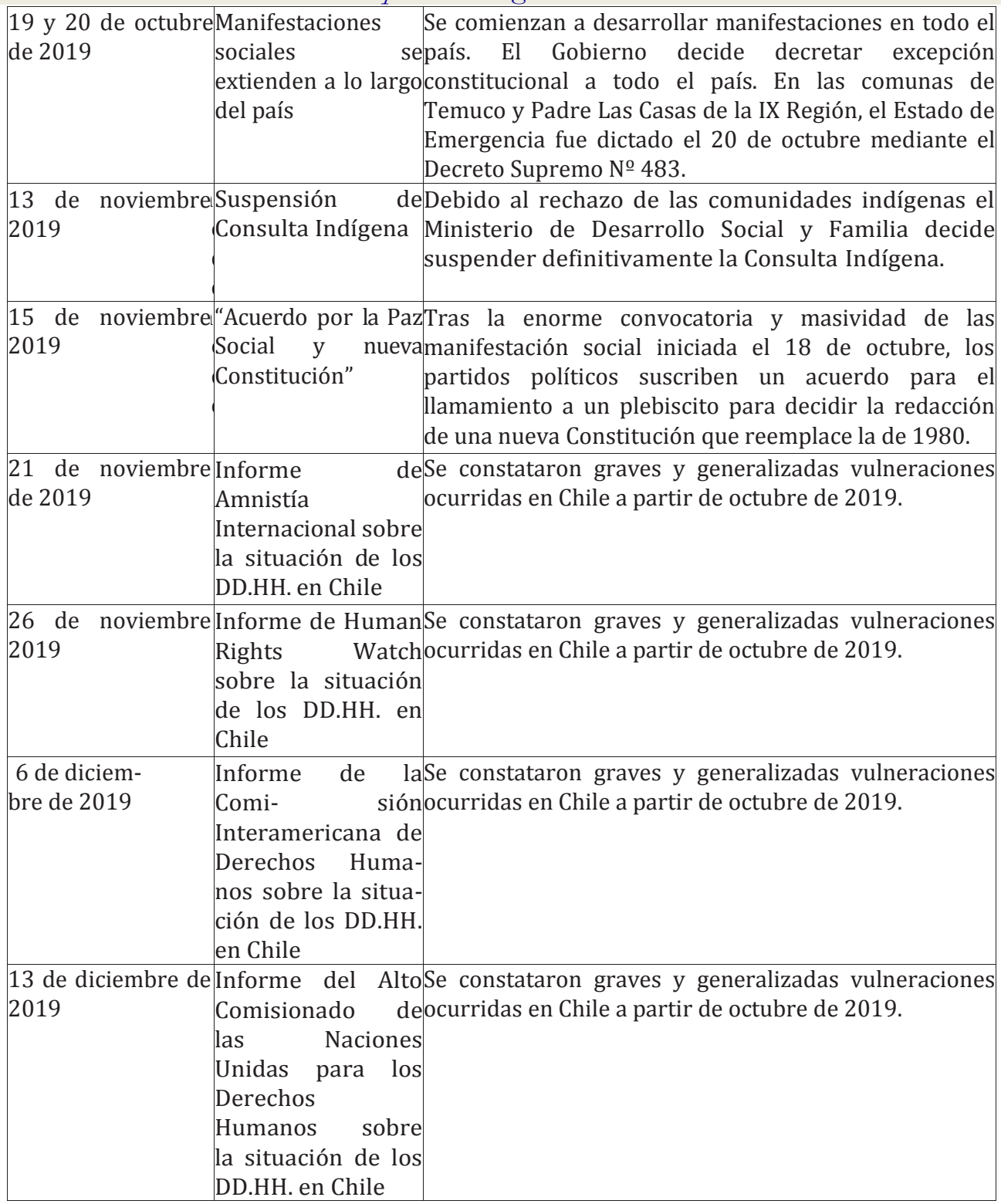

